\title{
UN TEATRO RELIGIOSO COLONIAL. EN ZUMPANGO DE LA LAGUNA
}

\author{
P O R \\ VICENTET. MENDOZA
}

\begin{abstract}
$\mathrm{D}$ URANTE una reciente visita que hice el día 5 de febrero de 1947, acompañado de la señora Florencia Müller, a la cercana población de Zumpango de la Laguna, Estado de México, a 54 kilómetros al norte de la sapital, tuve oportunidad de encontrar, en el barrio de Santa Maria, en el ángulo noreste del atrio, una curiosa construcción adosada a la pared derecha del templo y al frente, casi alineada con la fachada. Vista por el frente ofrece la circunstancia de estar levantada del suelo (foto 1) a una altura de dos metros, formando una plataforma de tres tramos construida sobre tres bóveđas rebajadas; en la primera de la izquierda existe una puerta practicable que comunica con la parte posterior; debajo de la segunda, un poco cargado a la izquierda aparece un sepulcro de construcción más reciente; en tanto que el tramo de la derecha se encuentra destruído, tal vez intencionalmente.

Dicha plataforma conserva tres pilastras de sección rectangular con sus basamentos respectivos que sostuvieron un techo del cual pueden apre-
\end{abstract}


ciarse los empotramientos de las vigas; la cuarta pilastra, o sea la del extremo derecho, no existe por estar adosada dicha construcción al muro derecho del atrio. En la parte posterior de la plataforma existe un lienzo de pared que en el tramo de la izquierda tiene una puerta que da acceso a un rectángulo que también estuvo techado en otro tiempo, no existiendo escalera de ninguna clase. En el tramo de la derecha se puede colegir que existieron dos paredes: la del fondo y la lateral, mas aparecen destruídas hasta una altura de 2 metros 20 centímetros (foto 2). E1 tramo del centro ofrece un interés especial, pues la plataforma se prolonga hacia atrás, formando un cuadrilátero, sobre cuyos lados y fopdo existen muros $y$ al frente un arco, formando todo una pequeña capilla con su media naranja y linternilla, siendo todo este dispositivo el que principalmente llamó mi atención, haciéndorne reflexionar sobre el objeto a que se destinara la construción. Toda ella se encuentra aislada del templo, excepto por un trozo de pared casi al frente del costado, quedando alejada, en cambio, de la sacristía, como formando un algo independiente.

Vista por la parte posterior muestra, entre el muro del templo y la pequeña capilla antes descrita, un hueco cuadrangular que debió haber estado techado, a la misma altura que el del frente, pudiendo apreciarse los empotramientos de las vigas que lo formaron en otro tiempo. Pegada al muro y a la altura de la plataforma delantera, queda el hueco de la puerta mencionada antes, sin escalera de ninguna clase, como se indicó. Al nivel del piso $y$ en el otro ángulo, hacia el frente, existe la puertecilla baja que permite pasar a la bóveda. ¿Qué objeto pudieron tener estas dos puertas a distinto nivel, una de ellas sin escalera de acceso? ¿Qué objeto pudo tener la plataforma de tres tramos con una puerta en un extremo y una pequeña capilla en el centro? a Con que objeto estuvo techada dicha construcción, tanto al frente como por la parte posterior en el tramo mencionado? ¿ Por qué el tramo noreste se encuentra destruído? Son contestaciones que mueven el presente escrito. Reflexionando sobre estas cuestiones he llegado a la siguiente conclusión: se trata del escenario de un teatro al aire libre construído expresamente para representaciones religiosas, probablemente coloquios o pastorelas.

\section{La forma aislada}

El hecho de encontrarse la construcción separada del templo y sus anexos, la sacristía, ete., hace pensar que fué concebida con dicha carac- 
terística, es decir, de modo que no interumpiese para nada las ceremonias y ritos litúrgicos, ni siquiera pasando por las dependencias privadas de la iglesia. Está pues ideado este pequeño teatro solamente adosado al templo, casi alineado a su fachada, y por último, formando el rincón derecho del atrio, el cual quedaba a cubierto de los vientos del noreste, propios de nuestros valles y procedentes de la llanura abierta hacia ese rumbo; mucho más sensibles durante las noches de invierno en que se verifican las representaciones de Navidad (foto $\mathbf{3}$ ).

\section{Alitura de la plataforma}

El segundo punto que hace pensar en que se trata de un escenario propio de un teatro al aire libre, es la altura de la plataforma, colocada a dos metros de altura, o por mejor decir, se encuentra el plano del escenario a la altura de los ojos de cualquiera persona. La primera idea que viene a las mientes es la de que se tratara de un corredor, un pequeño mirador o una baranda cubierta; pero se desecha desde luego esta posibilidad, pues la plataforma mencionada carece de pretil, citarilla u otra clase de muro sobre el cual generalmente se colocan macetas, tiestos o simplemente están construídas a una altura de ochenta centimetros o un metro, cuando más. Esta circunstancia se refuerza observando que ninguno de los tramos intercolumnios conserva huellas de construcción de barandillas, además de que la esquina del muro del templo se halla rebajada a fin de dar mayor visibilidad.

\section{La boveda}

La triple bóveda que resulta de la construcción de la plataforma que constituye el esceriario que se describe, parece haber sido dispuesta en la forma abierta que se ve, con el objeto de que, cubierta con lienzos o simples enramadas o, guirnaldas, manteniéndose a oscuras o con poca claridad, permitiría alos actores tener un lugar de descanso con asientos provisionales o les serviría para aderezar sus vestiduras, aguardando la señal del traspunte, utilizando entonces la puertecilla que da acceso al tramo techado del rincón, por donde les resultaba fácil penetrar al escenario propiamente dicho, utilizando una escalera portítil. El sepulcro que existe alli es de construcción relativamente reciente (foto 4 ). 


\section{La parte posterior}

La disposición total del pequeño teatro colocado en el rincón noreste del atrio, cerrándolo en el ánguio antes mencionado y teniendo acceso fácil por la parte de atrás, ofrece las siguientes circunstancias: en primera, la llegada de los actores, ya sea con sus vestidos definitivos o con sus ropas e implementos de caracterización, llevados consigo o por personas acompañantes, no distrae a la concurrencia, ni llama la atención, ni interrumpe la acción, sea cual sea el momento en que llegten al teatro. En segundo, la tramoya, la iluminación y luces de colores utilizadas en esta clase de representaciones pueden hacerse con la mayor amplitud desde la parte de atrás del atrio sin que el auditorio se dé cuenta de los preparativos. Tớa esta acción, más el movimiento de actores y personal, en dependencias interiores del templo, implicaria una agitación que trascendería al sagrado recinto, en tanto que en la forma en que se encuentra concebida y resuelta la construcción resulta perfectamente lógica y bien pensada.

\section{La plataforma del escenario}

E1 frente de la construcción constituye la parte esencial, pero sobre todo lo que es propiamente el escenario, o sea el plano total de los tres tramos a un solo nivel, incluyendo el del interior de la pequefia capilla, todo ello techado con el objeto de poner a cubierto a los actores de la intemperie y, al mismo tiempo, las tres columnas que resultan del dispositivo de la construcción, entrega una verdadera arquitectura que imprime majestad y realismo, a la manera del teatro griego, no sólo porque pueden colocarse guirnaldas, festones, cortinajes y demás artificios con que se decora un escenario, sino que puede transformarse por partes quedando dividido el escenario en cuatro porciones: tres al frente, más la capilla, reservándose ésta para escenificar el Portal de Belén y alguno de los otros tramos para la entrada al infierno.

\section{La capilla}

. Constituye la parte central, el corazón del escenario, el lugar en donde debe culminar la representación, por lo tanto, teniéndolo en cuenta el 
arquitecto, le dió proporciones de templo en miniatura, una verdadera capilla, casi de juguete, que purede ser transformada en gruta, para el ermitaño, en palacio de Herodes, en portal, inclusive, que a su tiempo puede iluminarse con las luces de la gloria, alumbrando el pesebre en que yace el niño Jesús, rodeado de la Virgen, de San José y los pastores. La proporción de su planta es cuadrada, lo que da una bóveda de dos metros setenta y cinco centímetros de altura total, incluyendo la linternilla que se sustenta sobre un tambor ochavado de setenta y cinco centimetros de altura. Al frente le da acceso un arco de medio punto. Esta construcción es la que adquiere un marcado interés en este pequeño teatro en el que pueden ser representadas diversas obras, pero más especialmente las pastorelas del siglo xviII (foto 5 ).

\section{Las puertas de acceso}

Quedó ya mencionada una puerta baja colocada en el primer tramo, adosada a la pared de la capilla, al ras del suelo, que sólo alcanza la altura de la bóveda, la cual da acceso al rectángulo posterior, formado por el muro de la capilla y el del templo. Si sólo se considera como paso entre I atrio y la sacristia, teniendo que agacharse y cruzar por debajo de la bóveda, no se explica el objeto de esta entrada pudiendo haberse fabricado una verdadera; mas considerando que se trata de utilizar la bóveda misma como cámara de la cual deben pasar rápidamente al escenario, resulta lógica esta disposición.

La puerta alta que conduce al escenario desde la parte posterior techada se encuentra al nivel del mismo, sin escalera, ni huellas de que la hubiese (foto 6). La única solución de esta anomalía es que para pasar los actores y personal de la obra desde la bóveda al escenario, debió utilizarse una escalera portátil de madera. Debió tener una verdadera puerta de madera o mampara que impidiese las corrientes de aire procedentes del nprte; aún queda el marco en que estuvo colocada.

También exisíć una tercera puerta que conducía a la parte baja de la capilla y que actualmente se encuentra tapiada, es de la altura de un hombre de mediana estatura $y$ de sesenta y cinco centimetros de ancho. Justamente este detalle viene a agregarse a in idea de un teatro, puies esta cámara cerrada debió utilizarse como vestidor para los personajes que tuviesen necesidad de cambiar de traje rápidamente y volver a hacer su presentación or ececon. 
Esta misma cámara tiene una lumbrera que da al frente y que igualmente se halla tapiada en la actualidad. Probablemente sirvió no sólo de respiradero o ventila, sino también para trasmitir órdenes a los actores que se encontraban en su interior.

\section{Escaleras}

Es muy posible que en determinados casos se haya colocado una escalera ancha al frente $y$ en el centro del escenario por donde tendrian acceso los pastores con sus ofrendas, los reyes con su servidumbre, si se tratase de la adoración de los Magos, y aun quizá, hubiera otra más en el costado izquierdo. Estas escaleras no anulan la función de la puerta del escenario, con la suya particular, pues su existencia se explica como una necesidad para las maniobras de utilería, maquinaria y tramoya, así como para la rápida aparición de personajes cuyos preparativos no debe presenciar el público.

\section{La parte destruida}

El tercer tramo de la plataforma o sea el de la derecha, se encuentra destruído y del mismo modo los dos lienzos de pared que formaban el rincón del escenario, quedando sólo la parte baja que cierra el ángulo. Visto por la parte de afuera no ofrece ninguna prolongación ni anexo, sino que es seguro que existieron, aunque no se puede afirmar que en la plataforma del escenario no hubiese algún escotillón tu otro modo de acceso. Especialmente en el rincón mismo en el que no quedan huellas del rebaje de la bóveda, sino que no obstante la destrucción en que se encuentra dudaría uno que en dicho ángulo haya existido bóveda. Esto hace pensar que justamente en este lugar hubo otro modo de acceso a la plataforma en el extremo izquierdo, con lo que el escenario tendria efectivamente dos entradas.

Desconcierta el encontrar roto y destruído este ángulo, siguiendo una construcción que debió ofrecer unidad y belleza al mismo tiempo. Ignoramos las causas que pudierón motivar esta destrucción.

\section{Las representaciones y su época}

La existencia de este teatro no escapa al conocimiento de los habitantes del barrio de Santa Maria, sino por el contrario, afirman que en 
otras épocas se hacian representaciones de Pastorelas y para ello existe el teatro construído en el atrio de su iglesia. Entre estas piezas recuerdan una cuyo título es Luebel y los mil pastores. $\mathrm{Y}$ aún vive don Ismael Pacheco que encabezaba todavía hace algunos años, las representaciones de Navidad que se ejecutaban en el centro de la población. El título de la obra mencionada nos revela en sí mismo su antigũedad, pues hasta la fecha no hemos encontrado entre las obras de esta indole semejante título; quizá se remonte al siglo xvir.

Otras representaciones son las de la Pasión, de las cuales aún quedan restos, tales como los fariseos que salen el miércoles santo para Ilevar al Señor del Santo Entierro en procesión. $Y$ es seguro que se realizaban los Pasos de la Pasión y que participaban en ellos los siete barrios del lugar, puesto que en el de Santiago tenía lugar Et Prendimiento, en el de San Lorenzo, Las Cruces, en el de San Miguel Los Azotes y en el de Santa María: El Encuentro; del mismo modo en los barrios de San Juan y de San Marcos. Entre los personajes que participan, se mencionan: Pilatos, Herodes, Caifás, el Cirineo y otros cuyo nombre en conjünto era el de La Judea. Todo llevado al cabo en forma solemne $y$ representable, conduciendo imágenes en procesión; pero actuando los personajes de carne $y$ hueso como en el caso del Cirineo, quien aparecía como un leñador que corta leña en el monte, formado expróeso para el caso; se le perseguía y obligaba a cargar la cruz del Nazareno. Del mismo modo hace apenas dos años se representó lo que llaman El Concilio, y es seguro que el teatrito de Santa María sirvió para llevar a efecto alguna parte del drama. El hecho de haber sido evangelizada esta región por frailes franciscanos nos induce a suponer que estas representaciones fueton introducidas por ellos, si no desde el principio de su gestion, por lo menos a fines del siglo xvr. Reforzándose este indicio por el hecho de aparecer en Tzintzuitzan, Mich., un teatro parecido a éste en iglesias construídas por franciscarios.

\section{$=$ \\ Capilla abierto}

La destrucción en que se encuentra la parte interior de la pequetia capilla to permite tener la seguridad de que en: su interior haya habido altares o retablos de madera. Es posible que los hubiera y en tal caso surge la posibilidad de que toda esta construcción fuese una capilla abierta como otras muchas que existen en diversos lugares del país. Dichas capillas fueron construidas para dar cabida a grandes multitudes que desde 
el atrio, asístían a la misa y demás ceremonias religiosas. Pero estas casi siempre tuvieron comunicación inmediata con el templo, estuvieron al nivel del piso y en lugares de fácil acceso. Las circunstancias señala. das antes, la carencia de una verdadera escalera por la cual pudieran subir el preste y sus acompañantes, hacen que si bien no deseche completamente la idea de una capilla abierta, sí me incliné mas a la opinión de que fuese el escenario de un teatro.

Si en el interior de la capilla hubo altar, este bien pudo haber sido aprovechado durante las festividades del Corpus como posa o descanso, pudiendo el sacerdote desde la plataforma dar la bendición a los fieles. Mas, ¿ para qué servirian la bóveda, la cámara interior debajo de la capilla, el espacio de la parte posterior techado y las puertas en la disposición en que se encuentran?

Para concluir diremos que esta construcción debe ser contemporá. nea $y$ aun simultánea a la del templo, a principios del siglo xvm, $y$ con más exactitud, hacia 1728, según una inscripción que existe en el interior del mismo. Siendo la construcción franciscana es fácilmente presumible que así como la mencionada orden creó las primeras representaciones de teatro edificante en México, haya sido ella misma la que pensara en la construccíón de estos teatros al aire libre con fines religiosos en el interior de los atrios, aislados del templo, pero al mismo tiempo formando parte de la arquitectura del mismo.

Siendo esta construcción de gran interes para el estudio de las construcciones religiosas en México, sumamente curiosa, pues no existe otra, que sepamos, sino en Tzintzuntzan, Mich., valdsía la pena conservarla y aun intentar sa reconstrucción, consistente en: reparar los muros y la parte de la plataforma destruída, así como techar el escenario y el rectángalo formado por la capillita y el muro del templo, con lo cual se lograrie quizá dar nuevamente auge a las representaciones populares religiosas como las Pastorelas y Coloquios en las noches de Navidad.

Una segunda visita realizada el 5 de mayo del año de 1947, en compañía de los señores Francisco de ia Maza, Gonzalo Obregón y José Servín Palencia, permitió tomar el suficiente número de fotografías, tanto en la parte anterior como posterior; descubrir in puerta tapiada y la lumbrera de la cámara interfor colocada debajo de la capilla, tomat medidas y acotaciones de la construcción, y hacer otras diversas observacio nes que reforzarion la opinión de que este pequeñ constracción, que a su conjumto viene a set como un jugriete adosado a muro del templo, es th teatro colonial al aire hibre. 


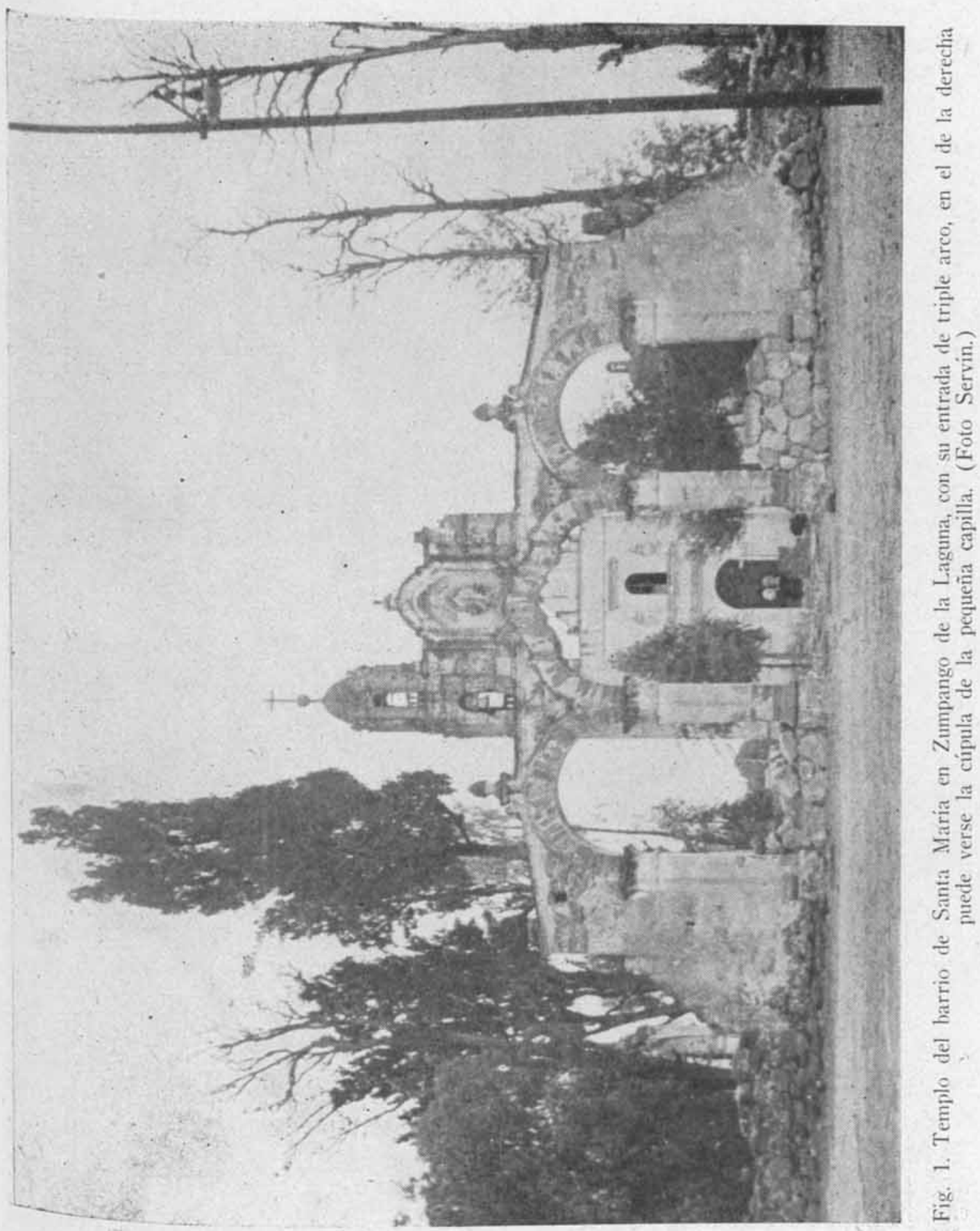




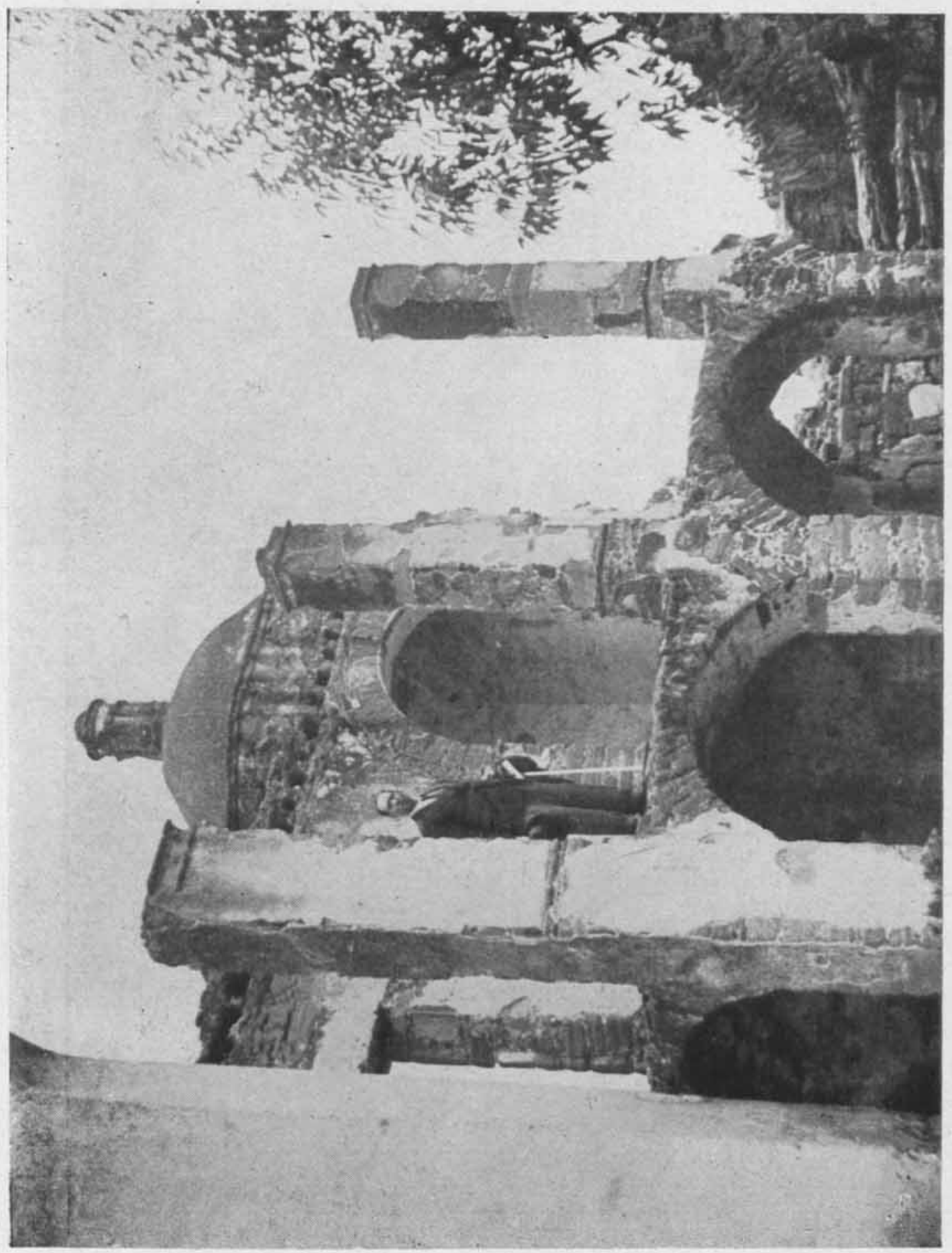




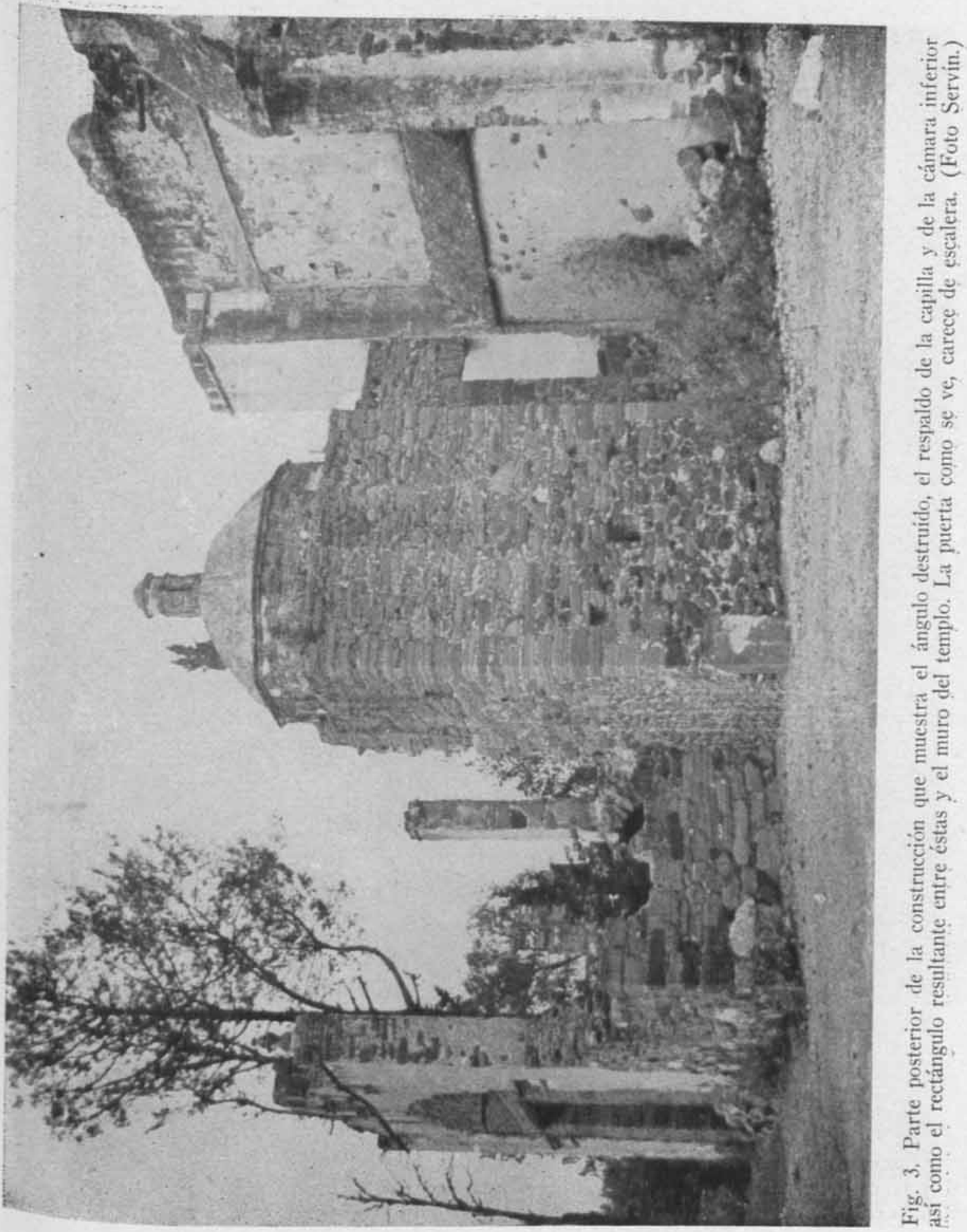




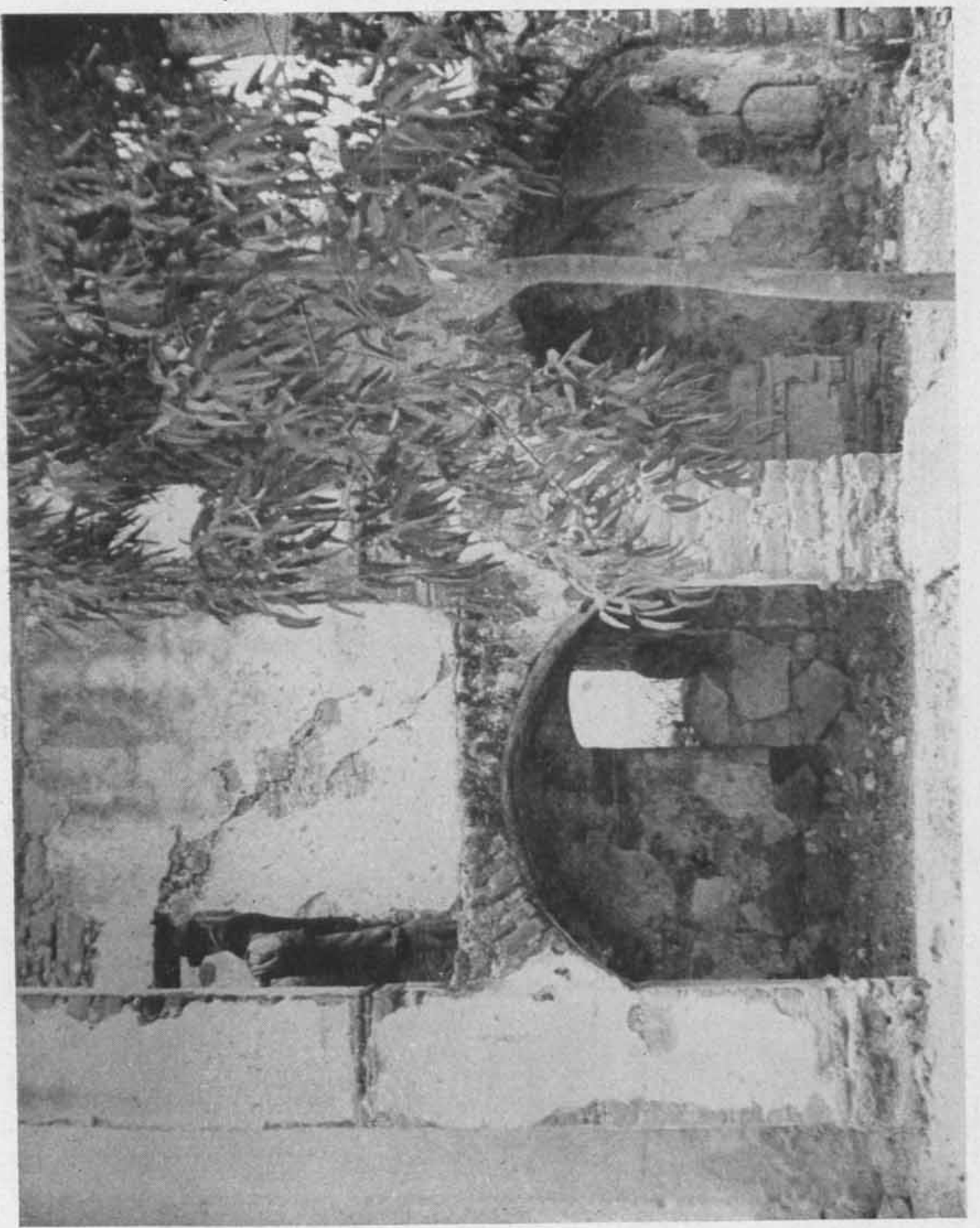

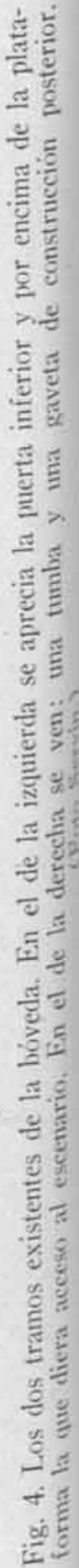




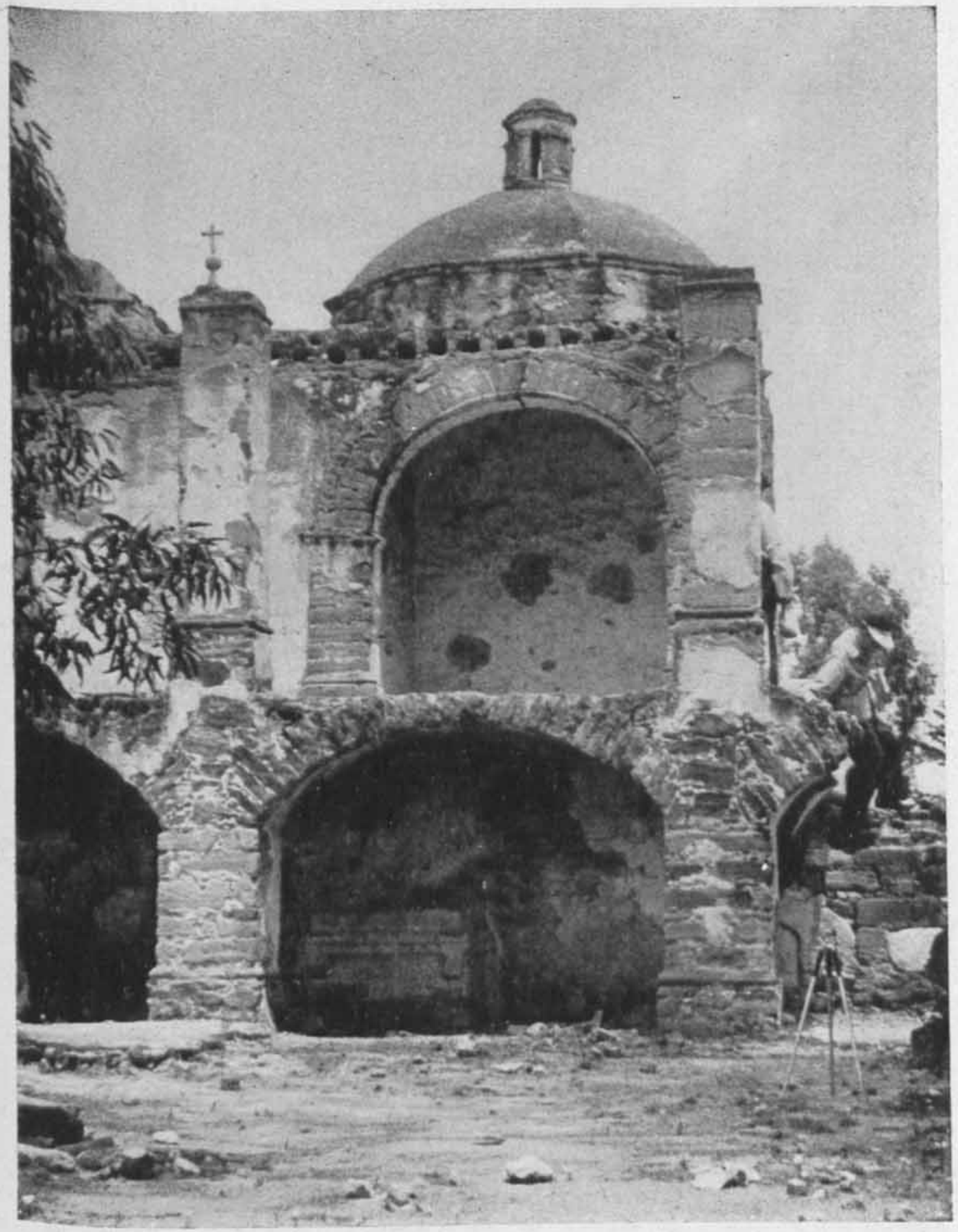

Fig. 5. Bóveda, plataforma, capilla y ángulo N. E. destruido, debajo del arco central se aprecia la lumbrera que da a la cámara interior. (Foto Servin.) 


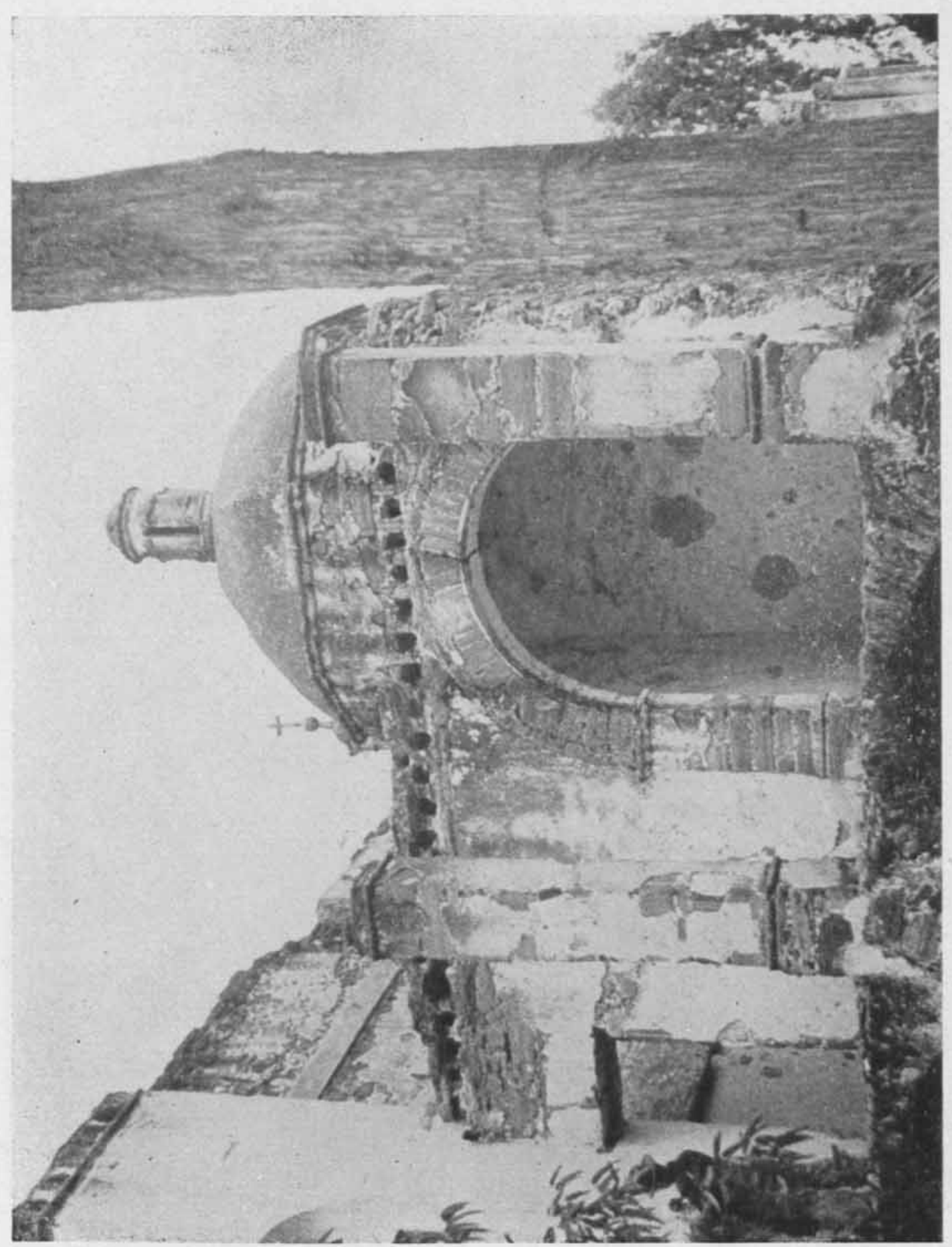

조

焉产

पूर

$\frac{5}{2} \frac{9}{9}$

कु

ํํำ

을

E

$\frac{\pi}{2}$

놀

$\supseteqq$

爱軠

ᄀ으

छี

䒿

표

8

을

सह

乌ु

$0>$

풀

을

표

전

존

함

爮

药

.

过

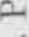

6

in 


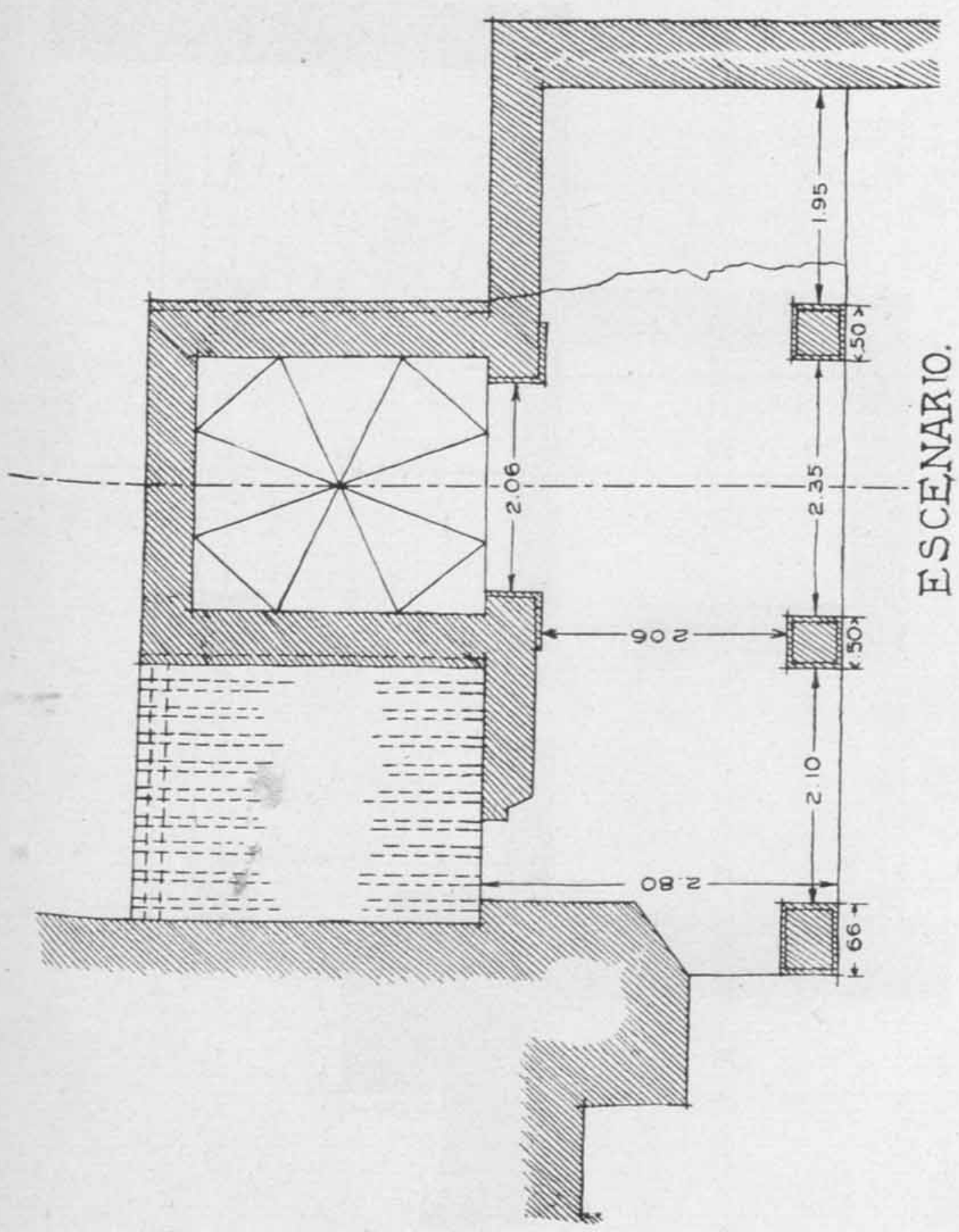


DOI: http://dx.doi.org/10.22201/iie.18703062e.1948.16.462

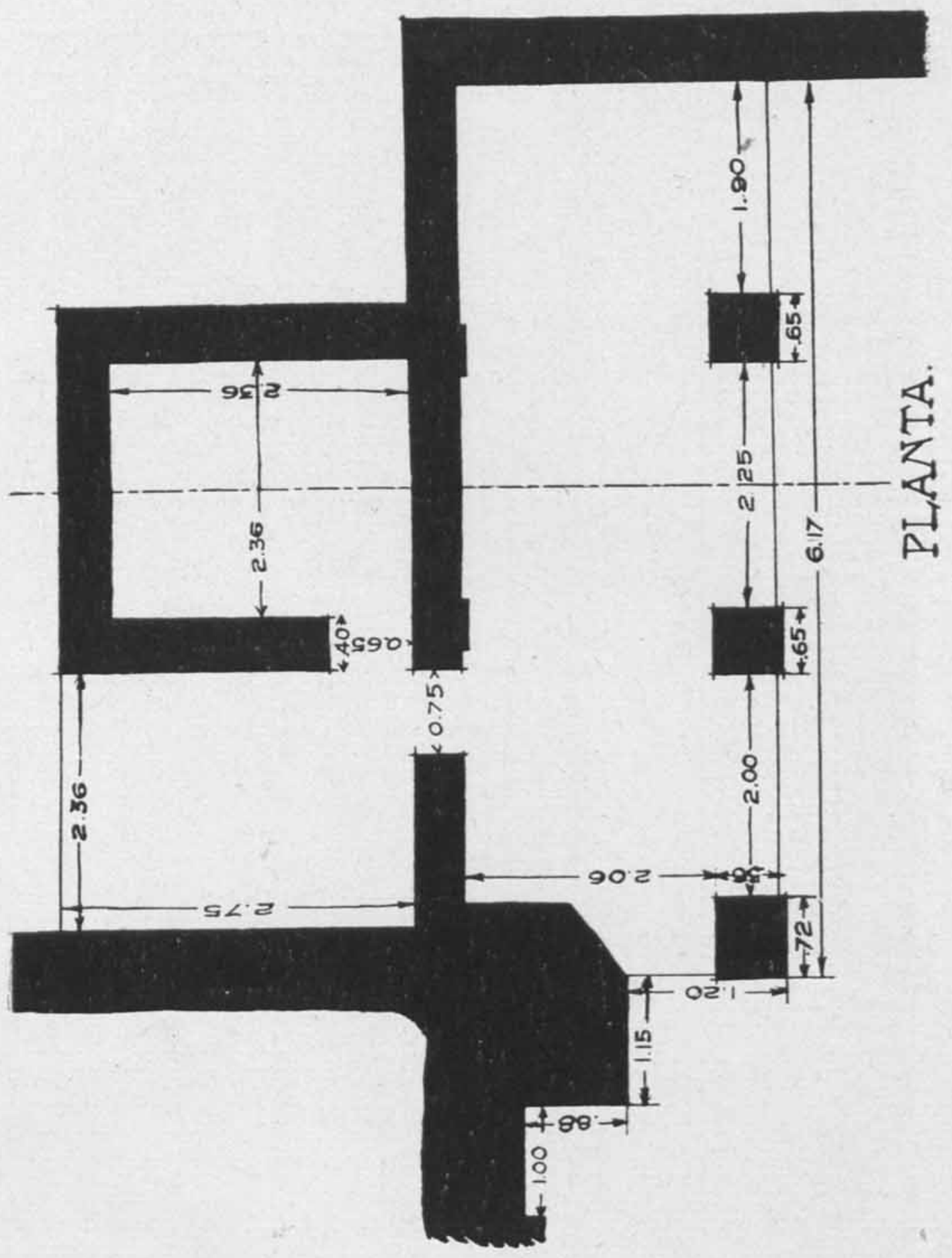


DOI: http://dx.doi.org/10.22201/iie.18703062e.1948.16.462

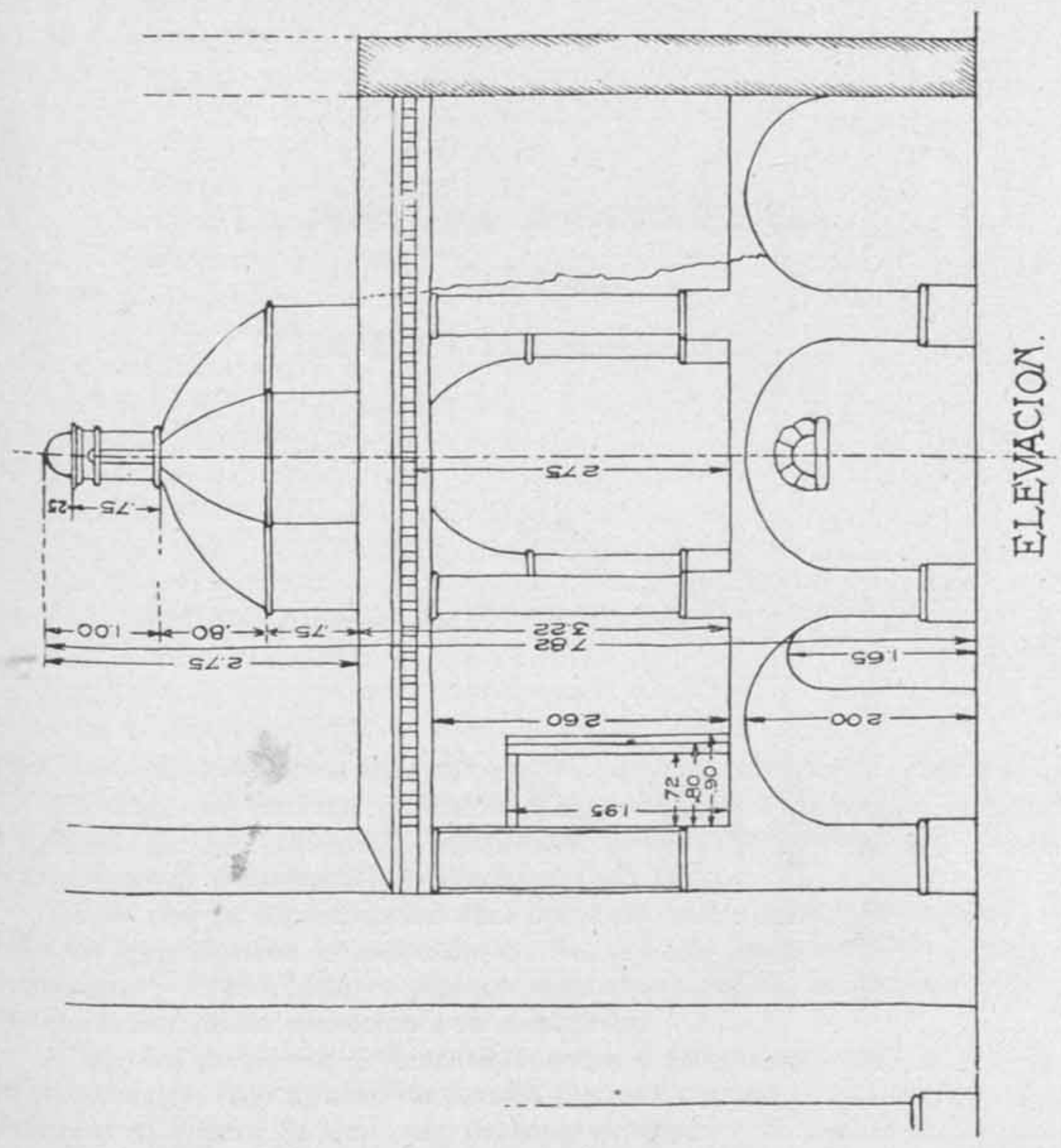

